\title{
Design Research Study: Investigation of Increasing Elementary Student's Spatial Ability Using 3Dmetric
}

\author{
*Mohammad Faizal Amir, Universitas Muhammadiyah Sidoarjo, Sidoarjo, Indonesia \\ Chusnul Chotimah, Universitas Muhammadiyah Sidoarjo, Sidoarjo, Indonesia \\ Rifki Afandi, Universitas Muhammadiyah Sidoarjo, Sidoarjo, Indonesia \\ Hendra Erik Rudyanto, Universitas PGRI Madiun, Indonesia \\ Isa Anshori, UINSA Surabaya, Surabaya, Indonesia
}

\begin{abstract}
In Indonesian National Curriculum in Indonesia, students at the elementary school level are required to master the geometry shape and sphere which in fact also requires spatial ability. At their level of thinking, elementary students need a concrete object to realize abstract spatial abilities in the minds of students so that the thinking becomes concrete or more real. Research Design Research is needed to solve local spatial geometry problems. 3Dmetric media developed based Augmented Reality applied to investigate the spatial ability of students. The result of the research shows that using the research design research, the application of 3Dmetric media is done by quantitative and qualitative spatial investigation to increase the spatial ability of students on the activity hypothesis of elementary school students.
\end{abstract}

Keyword--- design research, investigation, spatial reasoning, 3Dmetric media.

\section{Introduction}

NCTM has defined 5 standards of content in the curriculum of mathematical standards, namely numbers and operations, problem solving, geometry, measurement, and opportunity and data analysis [1], [2]. In the standard geometry content there are elements of visualization use, spatial reasoning and modeling [3]. This shows that spatial ability is the demand of curriculum that must be accommodated in classroom learning. In an observation conducted at SDN Lemahputro 1 Sidoarjo class 4B, it was found that 30 out of 36 students can not draw and can not distinguish between geometric sphere elements, ie between diagonal sphere and diagonal faces. They also can not be visualized geometric spheres that are rotated. In fact, the elements of geometry are axioms (fundamental) [4] and intuitively [5] must be understood by elementary school students [6].

At a concrete and operational elementary school thinking development stage, in order to understand a material, students must be called an activity or an intermediary connected with a real object or a real event acceptable to their reasoning [7].

Spatial ability, defined as the ability to visualize an object geometry from different angles, rotation and integration or integration of parts of a given object [8][9][10][11], can be improved and investigated further through 3DMetric media based on Augmented Reality (AR) technology[12]. AR media is an integration of digital elements that are added to the real-world in real-world (real-world data) and follow real-world environments and can be applied to mobile devices [13][14][15].

Design Research is the research method used to resolve local problems of teaching by developing teaching materials [16]. Therefore, by applying design research, media 3Dmetric is hoped to increase students spatial geometry capability and to be investigated further.

\section{Methodology}

Design Research has 2 perspective approaches to solve local student problems, it is the development of instructional materials and the investigation of its implementation [16],[17]. This study aims to investigate the use of 3Dmetric media in improving the ability of elementary school students. The research data consisted of two data, quantitative data obtained from the test results [18] the spatial abilities of each student's cycles, qualitative data obtained from the investigation results of activity observations [19] students in the Hypothetical Learning Trajector [16]. The subjects were 36 students of Class IV B SDN Lemahputro 1 Sidoarjo. The stages of design research study are Preliminary Design, Teaching Experiment and Retrospective Analysis. 


\section{Result and Discussion}

A. Preliminary Design

The premilinary design stage of this research is the development of HLT (Hypothetical Learning Trajectory) based on the student's spatial activity hypothesis which includes [20] 1) predicting the gemetrical sphere image when the aphere is rotated, 2) connecting visual parts on face of geometrical sphere, 3) drawing objects around by representing the geometry model, 4) visualizing the geometrical sphere into nets and vice versa, 5) predicting the visual geometrical sphere when viewed from another point of view.

Developing HLT should also be synchronized with instructional objectives[17], The following explanation is the making of HLT in curriculum applicable in Indonesia grade 4 of elementary school.

Education Unit: Elementary School (SD)

Subject: Mathematics

Class / semester: IV / 2

Competency Standards

: 8. Understand the geometrical sphere properties simple and inter-relationship geometrical shapes

\section{Hypothetical Learning Trajectory I}

Basic Competence

: 8.1 Determining the properties of geometridal spheres

\section{Hypothesis of Activity 1 Media 3Dmetric}

- Students can draw a spinning geometrical once. The wake-up of this space can be clockwise or clockwise.

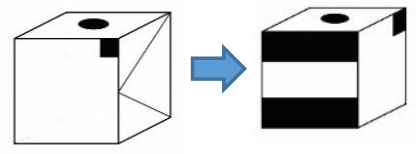

Clockwise

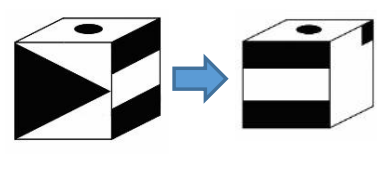

Counter clockwise

Fig.1. The rotation of cube clockwise clockwise and cointerand

- Students can draw 4-5 objects around correctly according to the understanding of spatial abilities. The average objects to be drawn by students are:

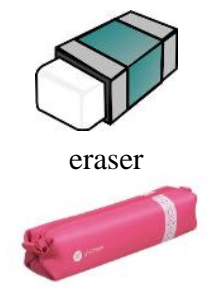

Pencil case

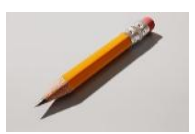

Pencil

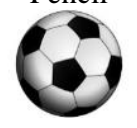

Ball

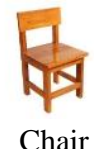

Fig.2. Guessing on things around students

Hypothesis of Activity 2 Media 3Dmetric

- Student can define at least one geometrival sphere element correctly

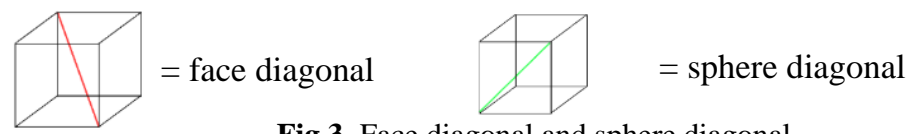

Fig.3. Face diagonal and sphere diagonal

\section{Hypothesis of Activity 3 Media 3Dmetric}

- Student can draw geometrical shape inside geometrical sphere with certain position. In the position of two parallel side diagonals can form a flat build called a diagonal sphere 
Basic Competence

Hypothetical Learning Trajectory II

Hypothesis of Activity 4 Media 3Dmetric

- Students can visualize geometrical sphere into nets with simple faces

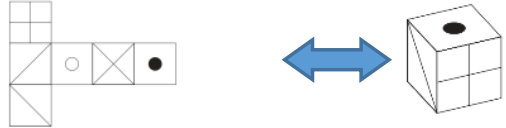

Fig.4. Cube and its nets

- For complex faces, student have difficulty to define the face in nets or sphere

Hypothesis of Activity 5 Media 3Dmetric

- Student understand and draw the upper partand sides of the miracle

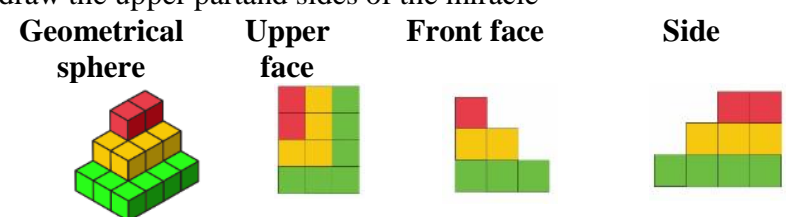

Fig.5. Geometrical sphere from several directions

B. Teaching Experiment

During the teaching experiment stage, 3D Metric media was evaluated for its visualization and usage based on a predeveloped HLT [17]. Visualization of 3D metric media use the tracker that has been arranged in the form of steps visual activity of students as in Figure 6. Figure 7-9 shows the interface or virtual results of the tracker (target object) HLT 1. While Figure 10-11 shows the interface or virtual results from tracker (target object) HLT 2.

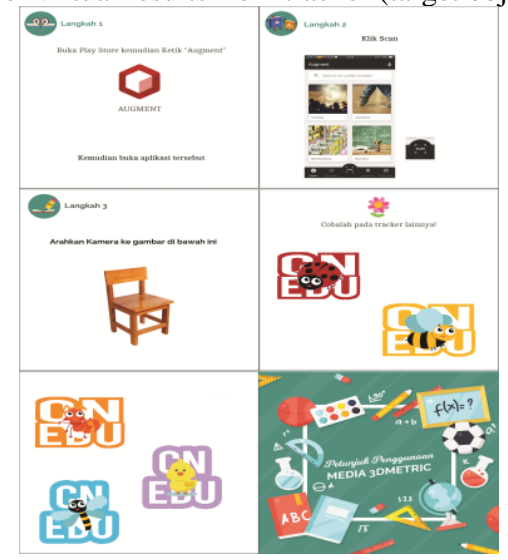

Fig.6. Tracker of spatial activity steps

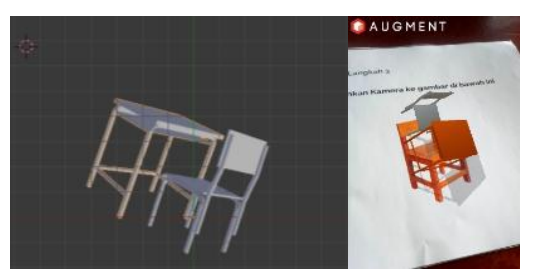

Fig 7. Interface Hypothesis of Activity 1

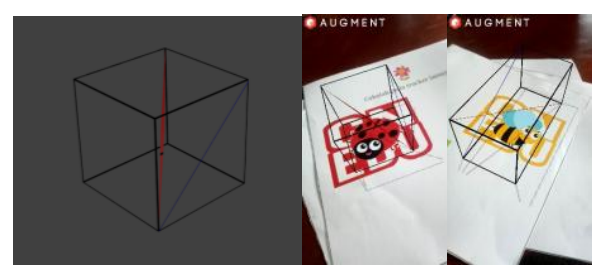

Fig 8. Interface Hypothesis of Activity 2 


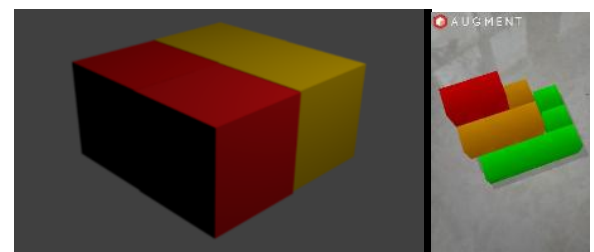

Fig 9. Interface Hypothesis of Activity 3

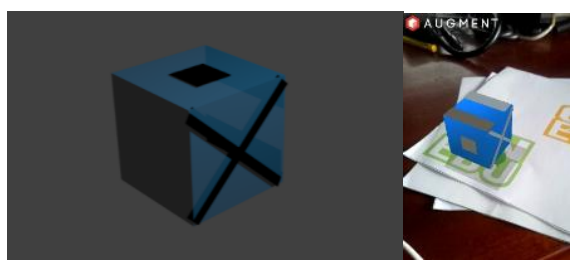

Fig 10. Interface Hypothesis of Activity 4

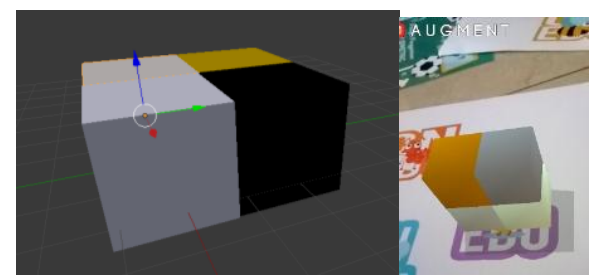

Fig 11. Interface Hypothesis of Activity 5

\section{Retrospective Analysis}

In the Retrospective Analysis stage, 3D metric media implementation was performed using retrospective analysis [17] i.e. investigation of spatial ability of students based on HLT consisting of activity hypothesis 1-5. To use 3Dmetric media, students are required to exploit [21] wake up space according to the activity hypothesis. The following figure 12 shows the student's activity while using 3Dmetric media.

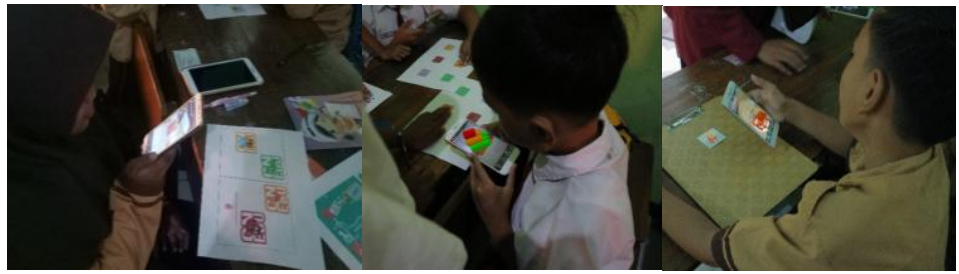

Fig 12. Student's activity while using 3 Dmetric media

Investigation of students' spatial ability is obtained through the student's spatial activity hypothesis during and after the use of 3Dmetric media on cyle 1 and cyle 2 . Each cyle consists of two meetings. The mean spatial activity and spatial abilities of students are shown in Figure 13 and Figure 14.

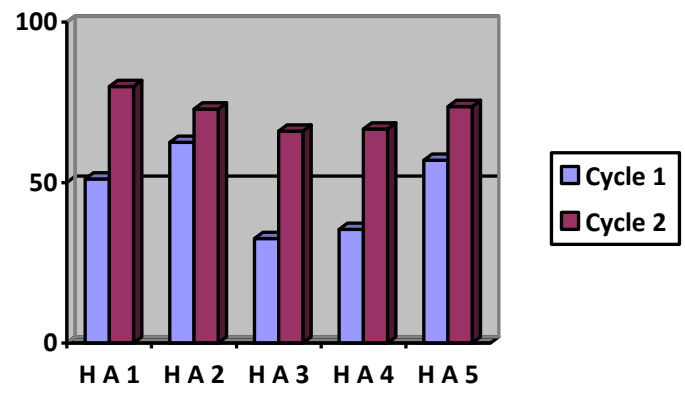

Fig 13. Students spatial activity 


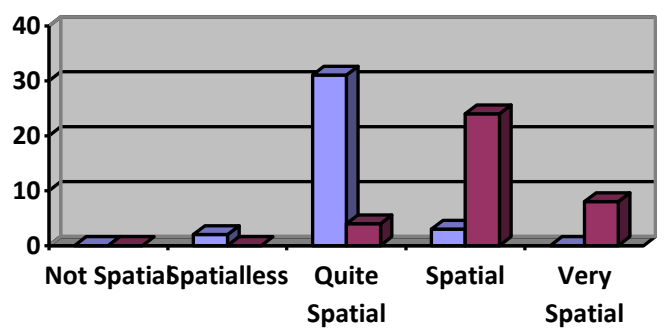

$\square$ Cycle 1 Cycle 2

Fig 14. Students Spatial Capability

Table 1. Descriptive statistics of students spatial capability

\begin{tabular}{cccc}
\hline Statistics of data & Pre-test & Pos-test & N Gain \\
\hline Mean & 49,94 & 71,67 & $\begin{array}{c}0,43 \\
\text { (medium category) }\end{array}$ \\
\hline Sd & 5,50 & 9,53 &
\end{tabular}

In Figure 13 Student activity on each HA (Activity Hypothesis) has increased. By using the conversion of quantitative data values to qualitative data [18], it can be seen that after cycle 2, no students are categorized as spatial and less spatial (fig 14). Students in moderately spatial categories decreased, but distributed increased in spatial and highly spatial categories. The increase in spatial ability of students is reinforced by descriptive statistical analysis using $\mathrm{n}$ gain and interpretation [22], in table 1 obtained n-gain $=0.43$ (medium category). This shows an increase in spatial activity of students through a kind of virtual manipulative media can help students in learning mathematics especially the concept of geometry [2],[9].

To investigate the depth of spatial ability of the students, a qualitative analysis was conducted on the post-test results of spatial ability of the students by taking the subjects purposively [19], this was done to probe the depth of spatial investigation of the students according to the qualitative needs of the researchers [23]. The depth of spatial ability is selected in 1 student with the highest spatial ability. Figure 15-19 is the result of the spatial skills of selected LCM students based on the activity hypothesis $1-5$.

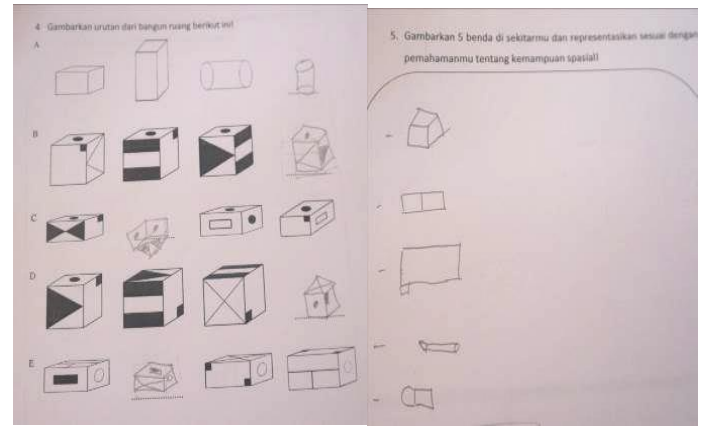

Fig. 15. LCM work result of activity hypothesis 1

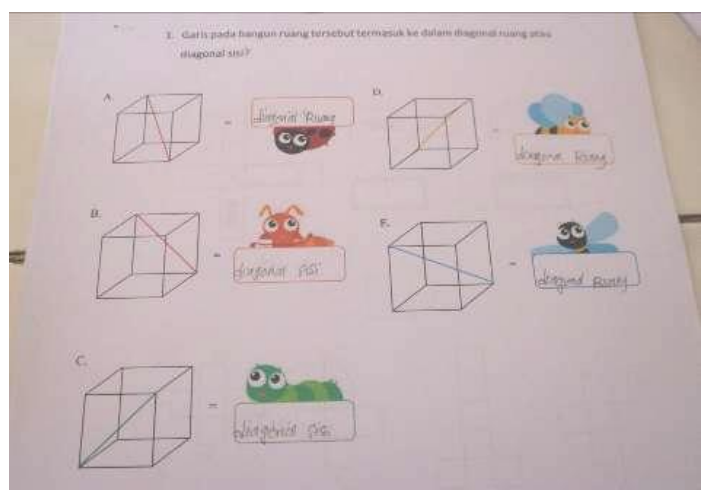

Fig. 16. LCM work result of activity hypothesis 2

*Corresponding Author: Mohammad Faizal Amir 


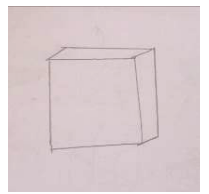

Fig. 17. LCM work result of activity hypothesis 3

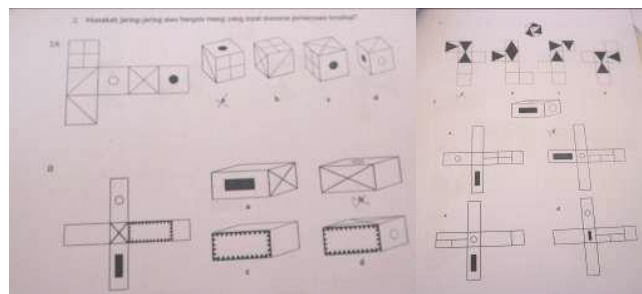

Fig. 18. LCM work result of activity hypothesis 4

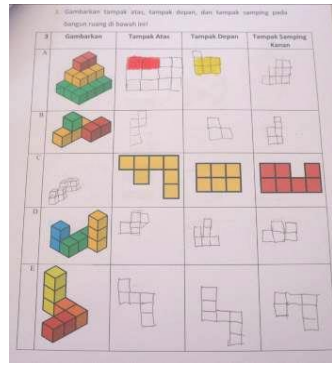

Fig. 19. LCM work result of activity hypothesis 5

The result of LCM student work on activity hypothesis 1 is on posttest at number 4 and 5 students can draw geometrical sphere when it is rotated once by answering 5 items in the post test correctly and correctly. In the drawing hypothesis by representing the geometry in the posttest the student draws 5 objects ie pencil, eraser, cube, front view of the board, and front view of the window.

The result of the work of the LCM student on activity hypothesis 2 is that in posttest number 1 there is an increase that the student can mention the answer correctly and accurately. Students responded with complete "sphere diagonal " or "face diagonal". Most students with low spatial skills simply answer "sphere" or "face" without being properly addressed. It can be concluded that students are able to mention elements of geometric sphere.

LCM student work result on hypothesis 3 at posttest number 6 shows that student can describe geometric shape in geometric sphere with certain positions. Students can draw two parallel lines so as to form a flat wake across the wake of space.

The result of the LCM student's work on hypothesis 4 is that in posttest number 2 students can visualize wake up space become the webs proved by selection of correct answer. Students analyze the spatial ability of how the sphere turns into a net when looking at the surface of the side that has a motive.

The result of the LCM student's work on hypothesis 5 is that in posttest number 3 the student can describe the front view, top view, and side view. However, students have difficulty in looking ahead from a geometrical sphere. The interesting part is that the student's privilege is able to describe the collection of spheres up by looking at the existing views.

ideal tool for investigating the depth of spatial capabilities, allowing students to view objects from different points of view and visualizing objects transparently [24], Using 3D metrics makes students quickly and easily manipulate geometrical models of image or sphere that are difficult to manifest in concrete or handmade objects [25]. Through this type of visualization, students can develop a deeper understanding of the relationship between wake-ups and nets [26]. For example, students can observe how to turn a wake of space into a net.

Spatial activity through AR media allows students to practice focus on reflection, reasoning [7], problem-solving processes [27] and High Order Thinking Skills in the field of geometry [28].

Thus, it can be concluded that the study design study using 3D metric media led to an increase in the hypothesis of activity in the HLT in each cycle. Progress of problem solving in research design is seen in each step of Preliminary Design, Teaching Experiment, Retrospective Analysis [29]. Research design research related to spatial geometry, also shows an increase in spatial geometry of elementary school students [30]-[31].

\section{Conclusion}

In a research design study with guided Hypothetical Learning Trajectory developed based on students' activity hypothesis, spatial geometry ability of elementary school students increased from cyle 1 and cyle 2 . The average of the spatial ability improvement of students showed medium category, but 3Dmetric media encourage students to has spatial and very spatial categories. Qualitatively, students' spatial virtualization is better in terms of looking at building space from different angles, imagining building space transparently, imagining, and being able to express the relationship between 
Jour of Adv Research in Dynamical \& Control Systems, Vol. 10, 06-Special Issue,

geometric sphere and webs. This process allows students to practice in focusing, reasoning, reflecting problem solving on the spatial geometry field.

\section{References}

[1] NCTM, "Why is Teaching with Problem Solving Important to Student Learning?," Natl. Counc. Teach. Math., vol. 13, no. 12, pp. 1-6, 2010.

[2] Ontario, Geometry and Spatial Sense, Grades 4 to 6. 2008

[3] F. Van Nes and J. De Lange, "Mathematics Education and Neurosciences: Relating Spatial Structures to the Development of Spatial Sense and Number Sense," Mont. Math. Enthus., vol. 4, no. 2, pp. 210-229, 2007.

[4] A. B. Bennett, L. J. Burton, and L. T. Nelson, Mathematics for Elementary Teachers: A Conceptual Approach. New York: McGraw-Hill, 2012.

[5] G. L. Musser, W. F. Burger, and B. E. Peterson, Mathematics For Elementary Teachers: A CONTEMPORARY APPROACH, Ninth. United States of America: John Wiley \& Sons, Inc., 2011.

[6] N. Sinclair and C. D. Bruce, "New opportunities in geometry education at the primary school," ZDM Math. Educ., vol. 47 , no. 3, pp. 319-329, 2015.

[7] R. Nagy-Kondor, "Spatial ability, descriptive geometry and dynamic geometry systems," Ann. Math. Informaticae, vol. 37, no. 1, pp. 199-210.

[8] S. Olkun, "Making Connections : Improving Spatial Abilities with Engineering Drawing Activities," Int. J. Math. Teach. Learn., no. April, pp. 1-10, 2003.

[9] R. Nagy-Kondor, "Importance of spatial visualization skills in Hungary and Turkey: Comparative studies," Ann. Math. Informaticae, vol. 43, pp. 171-181, 2014.

[10] S. a Sorby, "Developing 3-D Spatial Visualization Skills SherylA . Sorby," Eng. Des. Graph. J., vol. 63, no. 2, pp. 21-32, 1999.

[11] J. Y. Chao and C. H. Liu, "A case study on the spatial conceptualization abilities for sixth grade elementary students from urban, suburban and remote schools," Eurasia J. Math. Sci. Technol. Educ., vol. 13, no. 6, pp. 16751686, 2017.

[12] M. F. Amir, N. Fediyanto, C. Chotimah, and H. E. Rudiyanto, "Developing 3Dmetric Media Prototype through a Hypothetical Learning Trajector to Train Students Spatial Skill," J. Adv. Res. Dyn. Control Syst., vol. 10, no. 02Special Issue, pp. 1537-1542, 2018.

[13] P. Salinas and R. Pulido, "Understanding the Conics through Augmented Reality," EURASIA J. Math. Sci. Technol. Educ., vol. 13, no. 2, pp. 341-354, 2017.

[14] J. Yingprayoon, "Teaching Mathematics using Augmented Reality," Proc. 20th Asian Technol. Conf. Math., vol. 20, pp. 384-391, 2015.

[15] K.-H. Cheng, "Surveying Students ' Conceptions of Learning Science by Augmented Reality and their Scientific Epistemic Beliefs," EURASIA J. Math. Sci. Technol. Educ., vol. 14, no. 4, pp. 1147-1159, 2018.

[16] P. Cobb, J. Confrey, A. diSessa, R. Lehrer, and L. Schauble, "Design Experiments in Educational Research," Educ. Res., vol. 32, no. 1, 2003.

[17] K. Gravemeijer and D. van Eerde, "Design Research as a Means for Building a Konwledge Base for Teachers and Teaching in Mathematics Education," Elem. Sch. J., vol. 109, no. 5, pp. 510-524, 2009.

[18] S. Arikunto, Prosedur Penelitian. Jakarta: Rineka Cipta, 2012.

[19] Sugiyono, Metode Penelitian Kuantitatif, kualitatif dan $R \&$ D. Bandung: Alfabeta, 2013.

[20] M. F. Amir, C. Chotimah, N. Fediyanto, and H. E. Rudyanto, "Mengembangkan Prototipe Media 3Dmetric Melalui Hypothetical Learning Trajector untuk Melatihkan Kemampuan Spatial Siswa." Sidoarjo, pp. 1-10.

[21] P. Ivars, C. Fernández, S. Llinares, and B. H. Choy, "Enhancing Noticing: Using a Hypothetical Learning Trajectory to Improve Pre-service Primary Teachers' Professional Discourse," Eurasia J. Math. Sci. Technol. Educ., vol. 14, no. 11, 2018.

[22] R. R. Hake, “Analyzing Change/Gain Score.”Indiana University, Indiana, pp. 1-4, 1999.

[23] M. N. Marshall, "Sampling for qualitative research," vol. 13, no. 6, pp. 522-525, 1996.

[24] P. . Maier, "Spatial Geometry and Spatial Ability - How to Make Solid Geometry Solid?," Proc. Annu. Conf. Didact. Math., vol. 3, no. 1, pp. 69-81, 1996.

[25] H. Kaufmann, K. Steinbügl, A. Dünser, and J. Glück, "General Training of Spatial Abilities by Geometry Education in Augmented Reality," in Annual Review of CyberTherapy and Telemedicine, 2005, pp. 65-76.

[26] R. Raskar, G. Welch, and H. Fuchs, "Spatially Augmented Reality,” Methods, no. 919, pp. 1-7, 1998.

[27] M. F. Amir, F. N. Hasanah, and H. Musthofa, "Interactive Multimedia Based Mathematics Problem Solving to Develop Student s ' Reasoning,” Int. J. Eng. Technol., vol. 7, no. 2.14, pp. 272-276, 2018.

[28] M. Bower, C. Howe, N. McCredie, A. Robinson, and D. Grover, "Augmented Reality in education - cases, places and potentials," EMI. Educ. Media Int., vol. 51, no. 1, pp. 1-15, 2014.

[29] K. Gravemeijer and D. van Eerde, "Design Research as a Means for Building a Konwledge Base for Teachers and Teaching in Mathematics Education," Elem. Sch. J, vol. 109, no. 5, pp. 510-524.

[30] N. Jackiw and N. Sinclair, "Dynamic Geometry Activity Design for Elementary School Mathematics." pp. 1-9, 2005.

[31] B. L. Gerber, E. A. Marek, and E. P. Martin, "Designing research-based professional development for elementary school science and mathematics,” Educ. Res. Int., vol. 2011, no. November, pp. 1-8, 2011. 